broadcast antismoking commercials, smoking restrictions in restaurants and private workplaces, the radio and television ad ban, and the tar/nicotine listing requirement. ${ }^{3}$ The 1971 radio and television ad ban resulted in about a $27.8 \%$ savings in real ad spending for cigarette companies with no detectable reduction in demand. ${ }^{3}$ To be prudent, a total ad ban should be accompanied by controls on the introduction of new cigarette brands/varieties and by antismoking policies known to reduce consumption.

Such effective measures include excise tax increases, restaurant smoking restrictions, and broadcasting antismoking commercials. For each $10 \%$ increase in real cigarette price, a demand decrease of approximately $3.7 \%$ results. ${ }^{3}$ For each $10 \%$ increase in the smoking-age population covered by government smoking restrictions, a drop in demand of around $6.5 \%$ is seen. ${ }^{3}$ An optimal antismoking agenda would give highest priority to these efficacious policies.

William L. Simonich, PhD

Cancer Treatment Centers of America

Zion, Ill

1. Gostin LO, Brandt AM. Criteria for evaluating a ban on the advertisement of cig arettes: balancing public health benefits with constitutional burdens. JAMA. 1993 269:904-909.

2. Bergler R. Advertising and Cigarette Smoking: A Psychological Study. Bern, Switzerland: Hans Huber Publishers; 1981.

3. Simonich WL. Government Antismoking Policies. New York, NY: Peter Lang Publishing Inc; 1991.

In Reply.-Smoking is a highly complex and insufficiently understood behavior. Consequently, effective reductions in smoking behavior are likely to be achieved through a comprehensive public health strategy based on the best available data. At the same time, antismoking policies must be respectful of human rights and avoid promoting intolerance of socially unacceptable behaviors.

Dr Simonich is correct to warn that a ban on advertising could sharply reduce the cost of doing business for cigarette manufacturers. Since the cigarette market exhibits some price elasticity, significant increases in taxes may be necessary to maintain or increase the price of cigarettes.

We support a multidimensional public health approach to cigarette smoking, including tax increases, health education, smoking prevention, and cessation programs. We urge some caution regarding the remaining two suggestions made by Simonich-government-imposed smoking restrictions and a ban on the introduction of new brands of cigarettes.

Government-imposed smoking restrictions can represent a broad spectrum of policies with widely varying impacts on public health. While we support the restrictions on smoking in public areas that many states and municipalities have enacted, more aggressive government-imposed smoking restrictions could be perceived as punitive and unduly invasive. Most data on secondhand smoke are based on studies involving long-term exposure rather than casual transient exposure to smoke. ${ }^{1}$ For this reason, any government ban on smoking would require careful assessment of both its public health benefits as well as its potential intrusiveness. Policies, such as an ad ban, that focus attention and responsibility squarely on the tobacco industry for the risks of their product may have certain benefits over policies directed at individual smokers.

The proposal to ban the introduction of new cigarette brands is also problematic. While government could constitutionally ban the manufacture of cigarettes, it has chosen not to do so. If government continued to allow the manufacture of cigarettes but prohibited the introduction of new brands, it probably would be regarded as arbitrary and capricious. In order for such a law to pass constitutional muster, advocates would have to show why new brands pose a serious and special danger to public health over and above currently existing brands.

It is true that the empirical data to support a ban on cigarette advertising are equivocal. However, given the vast complexity of designing studies that show a causal relationship between advertising and smoking, any evaluation of a ban must rest on a careful assessment of many factors. The profound harms of smoking, the history of unsuccessful regulation of the industry, the unique characteristics of cigarettes in American life, and the minimum burdens on First Amendment values lead us to reiterate our conclusion that a ban on cigarette advertising would be an important part of a comprehensive public health strategy.

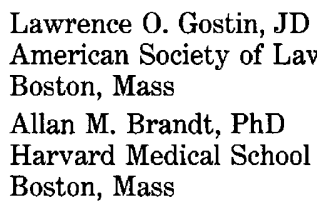

1. Respiratory Health Effects of Passive Smoking: Lung Cancer and Other Disorders. US Environmental Protection Agency, Office for Research and Development, Office of Health and Environmental Assessment; 1992.

\section{Nicotine Inhaler for Smoking Cessation}

To the Editor.-In a recent article, Tønnesen et al ${ }^{1}$ suggest that a nicotine inhaler in smoking cessation could be implemented in general practitioner offices with high success rates and that it would be "acceptable" to patients. In addition, the program is described as "low intervention." Results from their study do not support such statements.

Their study involved volunteers who were recruited through newspaper advertisements and who were motivated to quit smoking. Furthermore, subjects came to the clinic for a total of eight visits within 1 year, with each visit lasting "from 30 to 60 minutes." Subjects saw videotapes on smoking cessation, had group instructions about the use of the nicotine inhaler, had assessments with fiscal and biological parameters, and received individual counseling. Such broad and expensive interventions are admirable, but in my practice as well as that of most primary care physicians, I don't think they would be classified as low-intervention efforts. Moreover, I am surprised that despite such efforts, the placebo group had only a $5 \%$ successful smoking cessation rate at 1 year. In a prior study by Tønnesen et al, $23 \%$ of participants in a smoking cessation trial who were randomized to placebo were abstinent at 1 year.

The claim that nicotine inhalers will be acceptable to patients also seems premature given experiences with the use of the nicotine patch, the cost of which has been unacceptable for many of my patients. Will the nicotine inhaler, when it reaches the market (as I'm sure it will) cost as much or more than the patch when used at a per-unit dose? Furthermore, did the patients in the study receive their inhalers free of charge? If both answers are yes, then I expect that the inhaler will be less acceptable than envisioned, thus making success rates less than reported. Effectiveness trials with other nicotine replacement strategies have shown them to be less successful than that reported in controlled research reports. ${ }^{3}$

Finally, did patients truly use an average of 3.8 inhalers per day, with each inhaler on average good for 300 puffs, as reported? If true, then the average patient puffed 1.2 per minute every hour for 16 hours a day. Again, I am not sure my patients would find this acceptable.

Adam Goldstein, MD

University of North Carolina

Chapel Hill 
1. Tørmesen $P$, Nørregaard J, Mikkelsen K, Jørgensen S, Nilsson F. A double-blind trial of a nicotine inhaler for smoking cessation. JAMA, 1993;269:1268-1271.

2. Tønnesen P, Fryd V, Hansen M, Helsted J, Gunnersen AB, Forchammer H. Effect of nicotine chewing gum in combination with group counseling on the cessation of smoking $N$ Engl $J$ Med 1988;318:513-518.

3. Hughes JR, Gast SW, Keenan RM, Fenwick JW, Healy ML. Nicotine vs placebo gum in general practice. JAMA. 1989;261:1300-1305.

In Reply.-Our enrollment in the nicotine inhaler study was almost supersonic: all 286 smokers were enrolled in 5 days in the afternoon after working hours. Many subjects felt that the sessions were unsatisfactory due to the hurry and lack of personal contact. The subjects saw a 7-minute videotape at entry only. This could also be arranged in a primary care setting. We believe that the primary care physician could take advantage of his or her knowledge of, and partnership with, the smoker, and so the consultation time need not be more than 5 to 10 minutes. The low success rate in the placebo group in our study is a reflection of the minimal psychological support provided, combined with a relatively low degree of motivation to quit in moderately nicotine-dependent subjects. In contrast, we have attained higher success rates when we used nicotine gum in combination with group meetings. ${ }^{1}$

The inhaler was delivered free of charge, which might have enhanced compliance with the device. As the cost of the inhaler might influence optimal usage, reimbursement for the cost of the inhaler as well for other nicotine products would be desirable.

The subjects using the active nicotine inhaler attained a nicotine substitution that was $24 \%$ to $43 \%$ of their smoking levels. They used from one to 14 inhalers daily. It is not possible to see when the nicotine inhaler is empty. However, the subjects were told to replace the inhaler when they felt it had no more effect. It is our impression that they used the inhaler almost as often during the day as when smoking cigarettes but had to puff harder and more often compared with when using cigarettes. Using the inhaler does not seem to be more difficult than using the nicotine gum.

Last, we should optimize the implementation of smoking cessation in general practice since the efficacy of this treatment in its current state is as cost-effective as other preventive measures. ${ }^{2}$ Lack of time is not a legitimate excuse for not "treating" the smoking behavior.

Philip Tønnesen, MD,

Jesper Nørregaard, MD

Kim Mikkelsen, MD

Stig Jørgensen, MD

Bispebjerg Hospital

Copenhagen, Denmark

1. Tønnesen P, Fryd V, Hansen M, Helsted J, Gunnersen AB, Forchammer H. Effect of nicotine chewing gum in combination with group counseling on the cessation of smoking. $N$ Engl $J$ Med. 1988;318:513-518.

2. Fowler G. Educating doctors in smoking cessation. Tobacco Control. 1993;2:5-6.

\section{Persistent Ear Discomfort and Neck Pain}

To the Editor.-We read with interest the excellent synopsis of otorhinolaryngologic causes of persistent ear discomfort and neck pain by LeLiever. ${ }^{1}$ In our experience, in addition to eustachian tube dysfunction, an often overlooked cause of the symptoms described is activation of myofascial trigger points in the clavicular division of the sternocleidomastoid muscle (although some have questioned the basic concept ${ }^{2,3}$ ).

As characterized by Travell and Simons, ${ }^{4}$ when activated sternocleidomastoid trigger points are present and produce characteristic referred ear and neck pain on one side in the pattern described in the question posed to LeLiever, ${ }^{1}$ such points are usually found on the opposite side as well. This would account for the bilateral distribution of the patient's pain, as well as her increased pain on flexion of her neck.
Travell and Simons note that persons with such trigger points also often experience referred frontal headaches and referred autonomic phenomena, especially postural dizziness and equilibrium disturbances. ${ }^{4}$

Though some dispute the validity of the method, 5,6 we have had considerable success demonstrating such activated trigger points with liquid crystal thermography, validated by thorough physical palpation of the clavicular division(s) of the involved sternocleidomastoid muscle(s) and by disappearance of referred ear pain after treatment of the trigger point(s). Occasionally, chronic ear pain can result from activation of trigger points in the upper part of the deep layer of the ipsilateral masseter muscle; an activated trigger point in the medial pterygoid muscle can also produce chronic ear pain on the same side, but this is often accompanied by more jaw pain than was described in the case presented to LeLiever. ${ }^{4}$

David E. Conwill, MD, MPH

B. H. Cook, MD, PhD

University of Mississippi Medical Center Jackson

1. LeLiever WC. Eustachian tube dysfunction. JAMA. 1993;269:809.

2. Deyo PA. Back pain: the history and physical examination. JAMA. 1993;269:356 3. Deyo PA. TENS for chronic low back pain. $N$ Engl $J$ Med. 1990;323:1425.

4. Travell JG, Simons DG. Myofascial Pain and Dysfunction: The Trigger Point Manual. Baltimore, Md: Williams \& Wilkins; 1983:202-235, 249-259.

5. Cotton P. AMA's Council on Scientific Affairs takes a fresh look at thermography JAMA. 1992;267:1885-1887.

6. Swerdlow B, Dieter JNI. An evaluation of the sensitivity and specificity of medical thermography for the documentation of myofascial trigger points. Pain. 1992;48:205-213.

\section{Suicide Attempts and the Nicotine Patch}

To the Editor.-Within recent months, four pharmaceutical manufacturers have brought nicotine replacement patches onto the US market for the treatment of nicotine dependence. The package inserts for these nicotine patches warn physicians that the risks of nicotine replacement therapy in patients with known cardiovascular or peripheral vascular disease should be weighed carefully against the benefits of smoking cessation. We write to report the case of a patient with known coronary artery disease who attempted suicide by means of nicotine overdose using nicotine patches.

Report of a Case.-Our patient was a 44-year-old man who presented in October 1992 with a single episode of major depression and recurrent suicidal ideation. Diagnostic evaluation resulted in additional diagnoses of pathological gambling, alcohol dependence syndrome, and nicotine dependence. The patient had undergone coronary angioplasty in August 1992 for coronary artery disease. Two weeks prior to his October hospital admission, he attempted suicide by means of nicotine overdose. He placed seven 21-mg nicotine patches on his chest and began smoking cigarettes, two at a time. Prior to applying the patches, he had flushed the patch enclosures down the toilet. It was his intent to precipitate myocardial infarction, and he had planned to hurriedly remove the patches and similarly dispose of them once he developed chest pain. He also brewed and consumed a pot of doublestrength coffee. Approximately 2 hours into this attempt, having experienced no chest pain or other untoward symptoms, he became anxious that he might actually succeed in his suicide attempt and abruptly removed all the patches and discontinued smoking.

Comment.-We contacted Marion Merrell Dow Inc (oral communication with Elizabeth McManamy, RPH, Global Product Safety Specialist, February 1993), the producer of Nicoderm, regarding other reports of overdose or attempted overdose with Nicoderm. The pharmaceutical company had four reports of overdose on record, one of which was intentional 